\title{
Treatment of menorrhagia with two levonorgestrel intra-uterine systems in congenital uterine anomalies
}

\author{
A. Ullal • H. Ullal • M. Roberts
}

Received: 15 March 2007 / Accepted: 14 June 2007 /Published online: 24 July 2007

(C) Springer-Verlag 2007

Keywords Levonorgestrel intra-uterine system · Mirena . Uterine anomaly $\cdot$ Menorrhagia

\section{Case report}

We report a series of three consecutive patients diagnosed to have a uterine anomaly and treated with levonorgestrel intrauterine systems (LNG-IUS) for menorrhagia. All three patients had tried medical treatment and wanted more effective treatment. They were keen to conserve their uterus.

\section{Patient 1}

A 29-year-old lady had a transvaginal scan that showed a septum in the uterus. There were no fibroids and the endometrial echo in each cornu was linear. The septum extended from the level of the cervical isthmus to the uterine fundus. She did not plan a pregnancy for a few

Scan pictures by P. Moran

A. Ullal $(\bowtie)$

Department of Gynaecology, Sunderland Royal Hospital,

Sunderland, UK

e-mail: aartiullal@doctors.net.uk

H. Ullal

Department of Obstetrics and Gynaecology,

Royal Victoria Infirmary,

Newcastle Upon Tyne, UK

M. Roberts

Department of Gynaecology, Royal Victoria Infirmary,

Newcastle Upon Tyne, UK

years but wished to conserve her fertility. After counselling she opted to try the LNG-IUS. In view of the two uterine cavities, two IUSs were inserted, one in each cavity. The insertion was ultrasound guided and confirmed. The procedure was done under a cervical anaesthetic block.

\section{Patient 2}

A 42-year-old lady was diagnosed to have a septate uterus with the uterine septum extending from the isthmus to the uterine fundus with a single cervical canal on ultrasound scan. She had an IUS inserted into each cavity using local anaesthetic and their positions were confirmed using a 2-mm hysteroscope.

\section{Patient 3}

A 39-year-old lady had been diagnosed to have a uterus with two uterine cavities and two cervices at a caesarean section for a breech presentation. The IUSs were inserted under direct vision as the two cervical ostia were easily visualised via a speculum examination (Fig. 1). The lady wanted to attempt insertion without any anaesthetic and she was comfortable throughout the procedure.

At a 6-month follow-up visit, the women were amenorrhoeic and happy with the treatment. They intended to keep the IUSs in situ (Fig. 2).

\section{Discussion}

The levonorgestrel intra-uterine system is highly effective in reducing menstrual bleeding and has been shown to reduce the numbers of patients proceeding to hysterectomy 
[1]. The Cochrane Database review compared the various treatment options for menorrhagia. They concluded that there was no difference in quality of life scores but the LNG-IUS has lower costs than hysterectomy both at 1-year and 5-year follow-up. The LNG-IUS results in a smaller reduction in menstrual blood loss than endometrial ablation but similar patient satisfaction [2]. The current NICE guidance is to use the LNG-IUS as the first-line pharmaceutical treatment for menorrhagia provided long-term use of more than 12 months is anticipated [3].

Uterine malformations consist of a group of miscellaneous congenital anomalies of the female genital system [4]. There is a spectrum of anomalies of the uterus and cervix. They range from only a septum within a uterine cavity that may extend throughout the uterus and two distinct uteri. A bicornuate uterus is a uterus that has two horns and a heart shape; it has a wall inside and a partial split outside. The bicornuate uterus has a mean incidence of approximately $1 \%$ in the general population and is the second most common uterine anomaly.

Several cases have been reported of an embryo and an intra-uterine device sharing a bicornuate uterus [5]. Cases have been reported of uterine perforations during the insertion of an intra-uterine device when there is an unsuspected bicornuate uterus [6]. There is also a suggestion to mould the arms of a contraceptive device to insert two separate devices in the horns of the bicornuate uterus [7].

In all our cases the IUSs were inserted without moulding or cutting the arms of the device. There was no uterine perforation or expulsion of device. A single LNG-IUS has

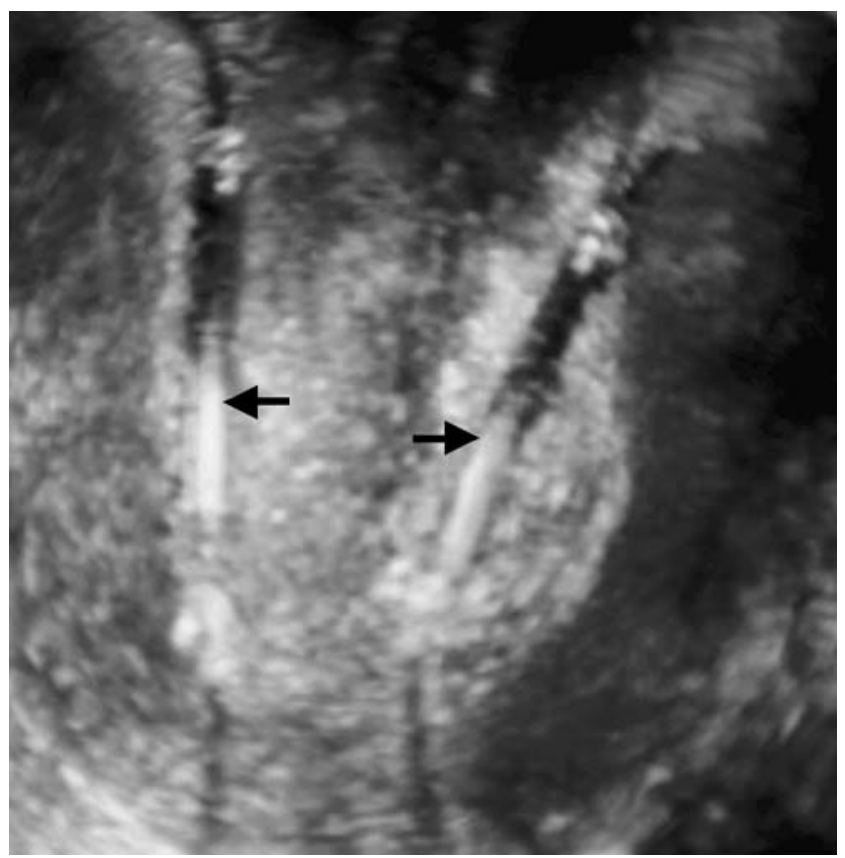

Fig. 1 Three-dimensional ultrasound picture from patient 3 showing one IUS in each uterine horn indicated by arrows

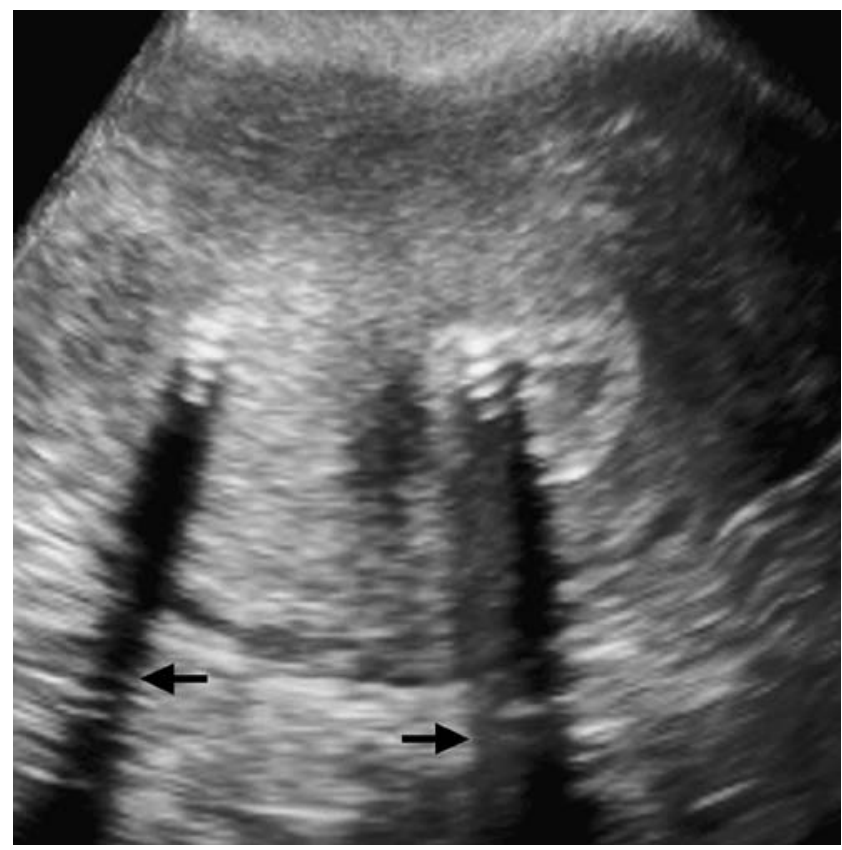

Fig. 2 Transvaginal ultrasound showing transverse image of separate IUSs in different endometrial cavities with associated acoustic shadowing indicated by arrows

been inserted in one horn of a bicornuate uterus for menorrhagia [8]. There are no reports of two LNG-IUSs being used in the same patient. Their use in this fashion is an out-of-licence use. The patients were informed of this and consent obtained. The rate of release of one LNG-IUS is minimal at $20 \mu \mathrm{g}$ in $24 \mathrm{~h}$ and therefore double the dose is unlikely to produce a significant systemic effect. Our high amenorrhoea rates may be due to the use of two devices.

\section{References}

1. Hurskainen R, Teperi J, Rissanen P, Aalto A-M, Grenman S, Kivelä A et al (2004) Clinical outcomes and costs with the levonorgestrelreleasing intrauterine system or hysterectomy for treatment of menorrhagia: randomized trial 5-year follow-up. JAMA 291:1456-1463

2. Lethaby AE, Cooke I, Rees M (2005) Progesterone or progesteronereleasing intra-uterine systems for heavy menstrual bleeding. Cochrane Database Syst Rev 4:CD002126

3. NICE clinical guideline No. 44-Heavy menstrual bleeding

4. Nahum GG (1998) Uterine anomalies. How common are they, and what is their distribution among subtypes? J Reprod Med 43(10):877-887

5. Furst A, Harats H, Mor-Yosef S (1992) Intrauterine contraceptive device and embryo sharing a bicornuate uterus: case report. Br J Gen Pract 42(356):129-130

6. Gupta SD (1970) Perforation of bicornuate uterus by intrauterine contraceptive device. J Obstet Gynaecol Br Commonw 77 (12):1140-1141

7. Nalbanski B, Cherveniashki S, Nalbanski B (1988) Intrauterine contraception in the case of a uterus bicornis after individual moulding of the arms of the pessary (in Bulgarian). Akush Ginekol (Sofiia) 27(1):69-71

8. Acharya GP, Mills AM (1998) Successful management of intractable menorrhagia with a levonorgestrel-releasing intra-uterine device, in a woman with a bicornuate uterus. J Obstet Gynaecol 18(4):392-393 